\title{
Os conceitos de justo e injusto em Aristóteles: entre EN V,1 e EN V,9
}

\author{
Mateus de Campos Baldin \\ mateus.baldin@gmail.com \\ Universidade Federal do Rio Grande do Sul (UFRGS), Porto Alegre, Brasil
}

resumo Alguns autores de Filosofia do Direito, em especial Michel Villey, tentaram apresentar o que pensavam ser a teoria aristotélica da justiça, fundamentando a partir dela suas próprias teorias. Para Villey, em específico, “o direito" seria a correta tradução do grego to dikaion. Defender com base em Aristóteles uma concepção de justo que recuse elementos subjetivos de uma teoria da ação é um erro. E esse erro parece estar em ignorar uma redefinição de to dikaion feita por Aristóteles no Capítulo 9 do Livro V da Ética Nicomaqueia. Ali, Aristóteles acrescenta às condições objetivas do justo e do injusto (EN V, 1-7) algumas condições subjetivas referentes àquele que sofre a ação. Somente após entendermos essas condições seremos capazes de entender corretamente a teoria aristotélica da justiça. Como Villey e outros autores as ignoram, eles erram ao interpretar Aristóteles e utilizá-lo para fundamentar suas próprias ideias.

palavras-chave Aristóteles; Michel Villey; Justiça; Ética Nicomaqueia

\section{Introdução}

Após o colapso do voluntarismo jurídico do século XIX, surgiu no direito, e em especial no direito privado, uma nova tendência (que de modo algum pode ser considerada uma escola ou movimento unificado) que procura analisar a justiça da relação intersubjetiva mediada pelo direito de uma forma objetiva, com uma minimização do uso de certos conceitos antes juridicamente essenciais como os de ação voluntária, vontade e escolha. $\mathrm{Na}$ esteira dessa tendência tornou-se possível o renascimento 
de institutos de direito romano e medieval dentro dos sistemas jurídicos contemporâneos. Institutos como a lesão, o enriquecimento sem causa e a responsabilidade civil objetiva, bem como cláusulas como a boa-fé objetiva, a função social e mesmo a culpa objetiva, já se tornaram comuns em nossas leis e decisões judiciais.

Para dar conta desses novos institutos que vieram a fazer parte de nossos sistemas de direito positivo, o velho modo voluntarista de encarar o direito não mais servia. Autores de diversas correntes procuraram por diferentes fundamentos para essa nova tendência objetivizante no direito. Enquanto alguns autores recorreram a escolas neohegelianas e neokantianas, outros recorreram a autores mais antigos, como a Aristóteles e Tomás de Aquino.

Alguns desses autores apelaram para a ideia de equidade, como por exemplo, o próprio Clóvis Bevilacqua, autor do Código Civil Brasileiro de 1916 (BEVILAQUA, 1903). Outros autores se valeram em grande medida de uma retomada de uma visão mais geral da exposição aristotélica da justiça e, em especial, do conceito aristotélico de justo (to dikaion), i.e., o adjetivo neutro apresentado como sendo o objeto da justiça, e não justo no sentido de pessoa justa (ho dikaios). Trata-se do justo enquanto qualificação de estados de coisas, e não de pessoas.

Entre esses últimos, tem especial relevância o nome de Michel Villey (VILLEY, 1977 e VILLEY, 2003, pp. 54-96), no direito em geral, e de Ernst Weinrib (WEINRIB, 1995) e James Gordley (GORDLEY, 2006) no direito privado. $\mathrm{O}$ que esses autores tão diferentes entre si quanto a objetivos e métodos têm em comum é sua visão de que a totalidade do direito (no caso deVilley) ou ao menos a totalidade do direito privado (no caso de Weinrib e Gordley) somente pode ser corretamente compreendida se recorrermos ao conceito aristotélico de justo e, mais especificamente, ao justo enquanto objeto da justiça particular. Para Villey, "O Dikaion só é concebido em seu sentido rigoroso no interior da justiça particular" (VILLEY, 2003, p. 74).

Uma característica comum desses autores é uma apresentação da teoria da justiça aristotélica que a isola da visão aristotélica mais geral sobre a ética e sobre a ação humana. Assim, pretendem eles, a teoria aristotélica da justiça pode ser compreendida sem se recorrer a sua teoria da ação e, por isso mesmo, sem se recorrer aos conceitos de ação voluntária e escolha. Essa característica, porém, não é exclusiva desses autores, podendo também ser 
encontrada em outros cuja preocupação central é a Ética e não a Filosofia do Direito. Também aqui a teoria aristotélica da justiça é por vezes apresentada sem maiores preocupações em ligá-la a uma teoria da ação moral (ver, e.g., BOSTOCK, 2000, pp. 54-73 e MILLER JR., 1995, pp. 67-86).

Essa forma de exposição da teoria aristotélica está talvez ligada à preocupação inicial de fundar o direito em uma visão puramente objetiva da justiça, entendendo-se por objetivo uma visão que não necessite recorrer a qualquer caracterização da ação humana ou dos agentes para que se fale de um estado de coisas como sendo justo ou injusto. É esse estado de coisas justo, e não as regras sociais ou o modo de ação humana sob essas regras, que seria o próprio direito.Villey, em especial, é claro em suas colocações, inclusive rejeitando a tradução tradicional de to dikaion por "o justo" e adotando a tradução "o direito":

Mas, o "direito", no sentido maior do termo, não designa a profissão ou a atividade dos juristas; mostra-se como uma coisa que o jurista busca, estuda, em torno da qual parece gravitar o ofício do jurista. A contribuição mais original da doutrina do direito de Aristóteles é precisamente a análise do termo justiça e, contudo, distinto desta: to dikaion - cuja melhor tradução em língua francesa é "o direito", e que os romanos da época clássica traduziam por jus. No livro V da Ética o direito (to dikaion) mais do que a justiça (dikaiosunê) constitui o tema principal. (VILLEY, 2003, p. 69) ${ }^{1}$.

O objetivo dessa exposição é demonstrar como estas interpretações objetivizantes do conceito aristotélico de justo são incompletas e, portanto, equivocadas. A tese que aqui defenderei é a de que interpretações do justo como sendo "a coisa justa" em sentido inteiramente objetivo, i.e., sem referência à ação voluntária, deixam de lado o grande papel que Aristóteles dá à voluntariedade na relação intersubjetiva de justiça, um papel decisivo para se poder julgar corretamente ações, situações e estados de coisas como justos ou injustos. Assim, dentro do próprio conceito de justo, através da análise da injustiça (hê adikia), parece estar incluída uma condição voluntarista, por assim dizer. Ou seja, uma condição que faz referência a conceitos como ação voluntária.

Isso que considero como insuficiência na interpretação do conceito aristotélico de justo está, creio, na leitura incompleta do Livro V da Ética 
Nicomaquéia. Acredito que essa insuficiência possa ser explicada pelo fato de que autores como Villey, Weinrib e Gordley preocupam-se exclusivamente com a definição aristotélica do justo contida no Capítulo 1 do Livro $V$ da EN, ignorando uma espécie de redefinição ou aprimoramento da definição feita por Aristóteles no Capítulo 9 do mesmo livro.

Uma outra conclusão, embora indireta, de minha exposição, será a de que um mesmo conceito de justo aparece tanto em suas instanciações ligadas à justiça particular quanto nas ligadas à justiça geral. Desse modo, se minha exposição estiver correta, devemos rejeitar também a tese de Villey de que o "sentido rigoroso" de to dikaion se dá apenas "no interior da justiça particular" (VILLEY, 2003, p. 74).

Defenderei que as diferenças entre essas duas definições de to dikaion, i.e., a do Capítulo 1 e a do Capítulo 9 (e não as diferenças entre o to dikaion da justiça geral e o da justiça particular) ${ }^{2}$ são cruciais para se entender por que as teses errôneas acima mencionadas, i.e., as de que a) o direito é apenas o estado de coisas justo e b) a correta compreensão dos institutos jurídicos não necessita fazer uso de conceitos pertencentes a uma teoria da ação voluntária, não decorrem da teoria aristotélica da justiça. Quais são, então, as diferenças entre as definições de justo no Capítulo 1 e no Capítulo 9?

\section{As definições do justo e do injusto em EN V,1}

Aristóteles inicia o Livro V da Ética Nicomaquéia com a observação de que a investigação da justiça (hê dikaiosunê) deve seguir o mesmo procedimento da investigação anteriormente feita acerca das demais virtudes, e este procedimento é a análise das opiniões reputadas (ENV,1 1129 a 5-6).

Vemos que todos querem dizer por justiça aquela disposição moral do justo, e que leva à ação justa e a desejar o que é justo; e de modo similar em relação à injustiça [todos querem dizer] aquela disposição que leva à ação injusta a desejar o que é injusto. E nós vamos assumir, para iniciar, que essa definição esteja em larga medida correta. (ENV,1 1129 a 7-11) ${ }^{3}$.

Assim, Aristóteles busca uma definição inicial de justiça com a qual poderemos trabalhar na análise que se segue: chamamos de justiça a disposição 
moral pela qual os homens se tornam aptos a fazer o que é justo, a agir justamente e a desejar o que é justo. E, de modo oposto, temos uma definição inicial de injustiça: chamamos de injustiça ao que leva os homens a agir injustamente e a desejar o que é injusto.

Deste modo, é central para Aristóteles a definição do justo e do injusto enquanto qualificadores de ações e estados de coisas para que seja feito um estudo do que é a justiça. Isso porque, em sua definição inicial de justiça já estão presentes os conceitos de justo e injusto. E isso implica que devemos antes comprendê-los para depois podermos compreender a disposição moral da justiça. E é exatamente isso o que faz Aristóteles na sequência do texto, logo após algumas observações sobre a homonímia dos termos tratados.

Justiça e injustiça são termos usados em diferentes sentidos, mas que em geral passam despercebidos, por estarem conectados (EN V, 11129 a 23-31). Esses sentidos são dados pela análise dos conceitos de injusto e de justo. E esses têm seus sentidos revelados pela análise dos conceitos de homem injusto (ho adikos) e de homem justo (ho dikaios).

Vamos, então, encontrar em quais sentidos se chama um homem injusto.

[O termo homem injusto] é tido como se aplicando tanto àquele que viola a lei quanto àquele que deseja mais do que o que lhe cabe, assim está claro que homem justo será tanto aquele que segue a lei quanto aquele que busca o igual. (ENV,1 1129 a 31-34) ${ }^{4}$.

Então, injusto será tanto o homem que viola a convenção ou lei da comunidade, quanto o homem que toma para si mais do que lhe cabe. E, por oposição, será justo tanto o homem que age de acordo com a convenção ou lei da comunidade, quanto o homem que toma para si exatamente aquilo que lhe cabe.

Aristóteles faz ainda duas distinções numa passagem posterior. A primeira é a distinção entre a ação injusta e o injusto, enquanto a segunda é a distinção entre ação justa e o justo. A ação justa é aquela que tem por objeto o justo, enquanto a ação injusta é aquela que tem por objeto o injusto (EN V, 71135 a 9-10).

Por sua vez, espelhando a distinção acima feita para o homem justo, pode-se distinguir dois sentidos para o justo e para o injusto: "Por um lado, o justo [é] o que está de acordo com a lei e o [que é] igual, por 
outro, o injusto [é] o que viola a lei e o [que é] desigual." (ENV,1 1129 a $34-35)^{5}$.

Então, em seu primeiro sentido o justo é definido como o que está de acordo com a lei ou convenção da comunidade política; ${ }^{6}$ enquanto em seu segundo sentido, é definido como o que é igual. O injusto é, por oposição, definido em seu primeiro sentido como o que é contrário à lei ou à convenção, e em seu segundo sentido como o que é desigual (ver KRAUT, 2002, p. 114, n. 25 e IRWIN, 1988, pp. 623-624).

E, desta distinção, segue-se aquela entre justiça geral e justiça particular. $^{7}$ A justiça geral é a justiça concebida como a totalidade da virtude exercida em relação a outros, tendo em vista o bem comum, ou a felicidade ou aquilo que compõe a felicidade da comunidade política (ENV,1 1129 b 14-19, 1129 b 25-1130 a 1). A justiça é, neste sentido, o bem dos outros, porque busca vantagem para os outros e não para si mesmo (EN V,1 1130 a 3-4). A justiça geral não é uma virtude moral entre as demais, mas a totalidade das virtudes morais exercidas para com outros, e buscando a vantagem dos outros (o bem comum de uma comunidade), em conformidade com a convenção da comunidade (ENV,1 1130 a 8-13). O objeto da justiça geral é, então, o justo (to dikaion) no sentido daquilo que está de acordo com a convenção ou lei da comunidade política.

A justiça particular, por sua vez, é uma virtude moral específica que, ao lado das demais, é parte da virtude da justiça geral (ENV,2 1130 a 1416). Trata-se da virtude que diz respeito ao modo de se lidar com bens exteriores, i.e., bens dos quais é possível ter mais ou menos (ENV,1 1129 b 1-6). Trata-se da justiça que tem por objeto o justo no sentido daquilo que é igual, ou seja, uma igualdade no que se refere a bens exteriores. $\mathrm{E}$ essa igualdade se dará em distribuições (EN V, 3), correções (EN V, 4) e trocas (ENV, 5).

Justiça é, assim, um termo que se refere a duas virtudes morais distintas, mas relacionadas no sentido de que uma delas, a justiça particular, é parte da outra, a justiça geral. Ambas tem por objeto o justo, em um caso entendido como o igual, em outro como o legal. E ambas buscam evitar o injusto; em um caso o desigual, em outro o ilegal.

Ocorrerá uma injustiça geral quando uma ação ou estado de coisas estiver em contrariedade com as virtudes exercidas para com outros. Ocorrerá uma injustiça particular quando uma ação ou estado de coisas 
atribuir bens exteriores de modo desigual às partes envolvidas, de acordo com os critérios de igualdade nas possíveis situações de distribuição, correção e troca apresentadas em ENV, 3-5.

Como se percebe, nas definições do justo e do injusto dadas em ENV, 1 não há menção a conceitos como o de ação voluntária. Embora na definição de ação justa esse conceito esteja obviamente presente, é a ação justa que é definida a partir do justo, e não o oposto. O justo é, aqui, aquilo que é justo, ou seja, uma situação ou estado de coisas que podemos predicar como justo, quer por estar de acordo com a lei, quer por promover uma igualdade quanto aos bens exteriores.

Não há espaço para a voluntariedade. Com isto, quero dizer que não cabe, pelas definições aqui dadas, aos agentes ou àqueles que sofrem com ações alheias estabelecer, por meio de suas escolhas, o que é ou não justo. ${ }^{8}$ Dizendo de outro modo, suas escolhas não parecem, aqui, ser capazes de afetar a justiça ou injustiça de suas ações ou dos estados de coisas delas resultantes. Estes serão julgados apenas por sua concordância ou não com a lei ou convenção, ou pelo resultado igual ou desigual, pouco importando o que os que agem e os que sofrem com a ação pensem sobre isso.

Esta interpretação é, excetuando-se obviamente a terminologia, semelhante àquelas apresentadas porVilley e Weinrib em suas obras. E, como vimos, é o justo no sentido daquilo que é igual queVilley considera como sendo o direito (ius) (VILLEY, 1977 e VILLEY, 2003, pp. 54-96). Mas a exposição aristotélica sobre o justo objetivo não se esgota aqui. Mais adiante no Livro V da Ética Nicomaquéia, ele volta a tratar do justo, agora em sua conexão com a ação voluntária.

\section{Voluntariedade, justiça e injustiça}

A voluntariedade e a involuntariedade já haviam sido tratadas no Livro III da Ética. Porém, o tema é retomado em EN V, 8, que trata especificamente da voluntariedade e da involuntariedade dentro do âmbito da justiça e da injustiça.

Aristóteles diferencia ação justa de ação conforme a justiça, e ação injusta de ação conforme a injustiça. Uma ação é justa se for realizada voluntariamente visando o que é justo, tal como definido em EN V, 1. 


\section{4}

Uma ação é voluntária quando está sob o controle do agente, sendo realizada por este com conhecimento de quem é afetado, do instrumento empregado e do resultado, excluindo-se acidente e compulsão externa. Uma ação é injusta se realizada nas mesmas circunstâncias, mas visando o injusto (ENV, 81135 a 19-28).

Porém, uma ação voluntária pode ser realizada por escolha ou sem escolha. É realizada por escolha uma ação voluntária que ocorra após uma prévia deliberação. Na ausência dessa deliberação, a ação é voluntária, mas não é realizada por escolha (ENV, 81135 b 8-11).

Uma ação que prejudique alguém pode ser feita a) na ignorância das circunstâncias relevantes; ou b) no conhecimento das circunstâncias relevantes, mas sem escolha, ou seja, sem prévia deliberação; ou ainda c) no conhecimento das circunstâncias relevantes e com escolha. Uma ação que prejudique alguém realizada na ignorância das circunstâncias relevantes (o primeiro caso) caracteriza um erro. $\mathrm{O}$ erro pode ser um infortúnio (se o resultado da ação for contrário à expectativa razoável) ou um erro perdoável (se o resultado da ação não for contrário à expectativa razoável, mas tenha ocorrido sem intenção de prejudicar quem foi afetado com a ação). Nenhum desses tipos de erro é culpável. Não há aqui ação injusta, apesar de ter ocorrido algo que, pela definição de justo que acabamos de ver em EN V, 1, caracterizaria uma injustiça. Uma ação que prejudique outrem realizada no conhecimento das circunstâncias relevantes, porém sem escolha (o segundo caso) caracteriza uma ação conforme o que é objetivamente injusto. Mas não caracteriza uma ação injusta. Somente uma ação que prejudique outrem e tenha sido realizada no pleno conhecimento das circunstâncias relevantes e por escolha (o terceiro caso) caracteriza uma ação injusta (ENV, 81135 b 11-1136 a 5).

Após tratar algumas outras questões referentes ao justo que escapam ao objetivo desse trabalho, em EN V, 9, Aristóteles se pergunta se é possível para alguém sofrer voluntariamente uma injustiça. O filósofo inicia dizendo que ser tratado justa ou injustamente parece ser o oposto de agir justa ou injustamente:

Pois é realmente possível sofrer voluntariamente uma injustiça, ou,

pelo contrário, sofrer uma injustiça é sempre involuntário, assim como agir injustamente é sempre voluntário? E novamente, sofrer o injusto é sempre voluntário, ou sempre involuntário, ou ora um, ora outro? E 
similarmente com o ser tratado justamente (pois agir justamente [é] sempre voluntário). (ENV, 91136 a 15-22) 9 .

Se é assim, existem quatro possibilidades para uma ação em relação a outrem: a) agir voluntária e justamente, b) agir involuntária e justamente, c) agir voluntária e injustamente, e d) agir involuntária e injustamente. Como contraponto a esses quatro modos de agir, há quatro possibilidades quanto a ser tratado, i.e., quanto ao sujeito passivo da ação de outrem, como nos mostra o texto: a) ser tratado voluntariamente de modo injusto, b) ser tratado involuntariamente de modo justo, c) ser tratado voluntariamente de modo injusto, e d) ser tratado involuntariamente de modo injusto.

Deste modo, o ser tratado justa ou injustamente pode ser voluntário ou involuntário, do mesmo modo como agir justa ou injustamente o pode. Aristóteles ilustra esse ponto dizendo que nem sempre alguém é tratado de modo justo voluntariamente, "pois alguns são assim tratados contra sua vontade" ${ }^{10}$ (ENV, 91136 a 22-23). Um exemplo seria um criminoso que recebe a pena justa apesar de não querer ser preso por seus crimes.

A partir daqui, Aristóteles coloca a discussão em novos termos, trazendo para aquele que sofre a ação (o sujeito passivo da relação de justiça) algo que anteriormente já havia estabelecido para aquele que pratica a ação (o sujeito ativo):

A seguinte questão pode também ser levantada, se sempre aquele que sofre a ação injusta sofre o injusto, ou ocorre como no caso daquele que age, pois pode-se ser parte no justo tanto como agente quanto como paciente? (ENV, 91136 a 23-27) ${ }^{11}$.

Pode-se agir de acordo com o que é objetivamente justo sem se realizar uma ação justa e pode-se agir de acordo com o que é objetivamente injusto sem se realizar uma ação injusta, porque as ações justas e injustas implicam fazer aquilo que é justo ou injusto voluntariamente. ${ }^{12}$ No caso daquele que sofre com a ação (o sujeito passivo de uma relação de justiça), seria possível, então, dizer que alguém pode sofrer o que é objetivamente injusto sem ter sofrido injustamente, pois sofrer injustamente implica ter sofrido contra sua vontade? 


\section{A redefinição do injusto em EN V, 9}

Aristóteles é levado a redefinir a ação injusta para poder responder corretamente a essa pergunta defendendo a tese de que é impossível para alguém sofrer voluntariamente uma injustiça (IRWIN, 1999, p. 236). Vejamos como procede seu argumento.

Primeiramente Aristóteles nos lembra que agir injustamente não é o mesmo que agir conforme ao que é objetivamente injusto:

Do mesmo modo, é claro que o mesmo se dá quanto ao injusto: pois não é o mesmo fazer o injusto e agir injustamente, e [não é o mesmo] também sofrer o injusto e sofrer injustamente, e o mesmo também com agir justamente e ser tratado justamente; pois é impossível sofrer o injusto sem que [a outra parte] aja injustamente, e sofrer o justo sem que [a outra parte] aja justamente. (ENV, 91136 a 26-29) ${ }^{13}$.

A relação de justiça pressupõe um sujeito ativo e um sujeito passivo. Assim, é impossível para o sujeito passivo ser tratado injustamente sem que o sujeito ativo aja injustamente. Do mesmo modo, é impossível que o sujeito passivo seja tratado justamente sem que o sujeito ativo aja justamente.

Como vimos anteriormente, para uma ação ser injusta não basta que tenha sido realizada de acordo com o que é injusto, mas também que tenha sido realizada voluntariamente: com conhecimento de quem é afetado, do instrumento e da maneira com que é afetado.

Como Aristóteles quer defender a tese de que "é impossível sofrer voluntariamente uma injustiça, ele é levado, então, a redefinir ou complementar a definição anterior de justo (to dikaion).

Isso porque qualquer tentativa de afirmar que ninguém aceitaria ser tratado conforme o que é objetivamente injusto não pode ser aceita integralmente em virtude da teoria aristotélica da voluntariedade, que exclui a necessidade de escolha deliberada para que uma ação seja voluntária. Desse modo, pode ser o caso que um incontinente voluntariamente, embora não deliberadamente, aceite que lhe seja feito o que é conforme o objetivamente injusto (ENV, 91136 b 2-3).

Assim, dizer que ninguém aceitaria ser tratado de modo injusto não é uma boa resposta para o problema. Para defender a tese de que é impossível ser tratado voluntária e injustamente ao mesmo tempo, Aristóteles 
precisa de uma nova definição de injusto, que complemente a definição inicial que, como vimos, ele aceita provisoriamente em ENV,1.

Não basta uma ação voluntária realizada conforme a injustiça para que se caracterize o injusto; da mesma forma que não basta uma ação voluntária conforme a justiça para que haja o justo. ${ }^{14}$ Isso porque aquele que sofre a ação pode sofrê-la voluntariamente. Assim, para que ocorra o injusto objetivo, é preciso que aquele que sofre a ação a sofra involuntariamente, ou seja, é preciso que a ação injusta do sujeito ativo da relação de justiça tenha sido feita contra a vontade do sujeito passivo.

Aristóteles pergunta-se se não deveríamos fazer uma modificação na definição inicialmente aceita em ENV,1:

Ou talvez essa definição esteja incorreta e devamos acrescentar a "causar dano conhecendo quem [a pessoa afetada], com o que [o instrumento utilizado] e o modo", [a fórmula] "contra a vontade [dessa] pessoa". Se for assim, embora um homem possa sofrer e possa ter o que é [objetivamente] injusto feito a ele, não pode sofrer [o injusto] voluntariamente, porque ninguém pode querer sofrer, mesmo o incontinente, que age contrariamente a sua vontade; dado que ninguém deseja algo que não julga ser bom, e o incontinente faz o que não julga bom. (ENV, 91136 b 3-9) $)^{15}$.

Feita essa adição à definição original, podemos dizer que uma pessoa pode ser prejudicada voluntariamente e sofrer voluntariamente o que é injusto, mas ninguém pode dizer que sofreu voluntariamente uma injustiça, nem mesmo uma pessoa incontinente.

Se for assim, então também o justo e o injusto devem ser redefinidos, necessitando-se verificar não apenas as condições objetivas (i.e., aquelas mencionadas em EN V, 1-7), mas também verificar se aquele que sofre com a ação ou estado de coisas o faz voluntariamente ou não. Se sofre voluntariamente, teremos o injusto apenas em seu sentido original (algo que não é em si justo), mas não em seu sentido próprio (algo que não é em si justo e que se produz contra a vontade de quem o sofre).

Isto vale tanto para a injustiça geral como para a injustiça particular? O texto de ENV, 9 parece não fazer esta distinção, pois prejudicar outrem pode ser resultado de qualquer ação conforme um vício ou contra a convenção, o que caracterizaria um injusto no sentido da injustiça legal ou 
geral. Além do mais, dada sua própria definição, a justiça particular é parte da justiça geral e, por conseguinte, o justo particular é também justo geral (embora o inverso não seja necessariamente o caso). Se é assim, Aristóteles acaba, então, por redefinir o justo e o injusto tanto em sua acepção geral quanto em sua acepção particular. Assim, um estado de coisas completamente injusto só pode ocorrer quando aquele que sofre a ação injusta a sofre involuntariamente.

Não basta, para que se possa falar de um estado de coisas como injusto, que ele seja o que é contra a convenção, nem que seja o que é desigual, mas é necessário também que aquele que sofre o prejuízo o sofra contra sua vontade. Assim, por essa mesma definição, ainda que um estado de coisas acabe por ser contra a convenção ou desigual (por exemplo, dando a alguém aquilo que não lhe cabe), ele não será completamente injusto se aquele que é afetado pela ação que causou tal estado de coisas a tenha aceitado voluntariamente. Caso quem sofra com essa ação a aceite voluntariamente, o estado de coisas resultante deve ser qualificado como ao menos relativamente injusto, quando não relativamente justo.

Assim, dada essa redefinição, temos dois conjuntos de condições que uma ação ou estado de coisas deve satisfazer para podermos qualifica-los de justos: condições objetivas (apresentadas en EN V, 1-7) e condições subjetivas (apresentadas em ENV, 8-9). Então, o justo e o injusto admitem variação de grau: do completamente injusto (nem as condições objetivas nem as subjetivas do justo são satisfeitas) ao completamente justo (tanto as condições objetivas quanto as subjetivas são satisfeitas), passando por situações intermediárias (apenas as condições objetivas, mas não as subjetivas, são satisfeitas; ou o inverso).

\section{Conclusão}

A conclusão a que podemos chegar aqui é de que Aristóteles é mais voluntarista do que pode parecer a um primeiro momento, e certamente mais do que o modo como o aristotelismo é apresentado pelos filósofos do direito que, como Villey, Weinrib e Gordley, que procuram ver no to dikaion apenas e tão somente um estado de coisas que pode ser apreciado sem referência à voluntariedade ou não da ação daqueles nele envolvidos. 
Como esses autores, em especial Villey, ignoram os Capítulos 8 e 9 do Livro V da Ética Nicomaqueia, eles se fixam apenas nas condições objetivas do justo, deixando de lado as condições subjetivas. Somente assim Villey pode falar em "coisa justa" ou "direito" como traduções de dikaion.

Porém, este "voluntarismo" aristotélico é radicalmente distinto do voluntarismo que prevaleceu no pensamento jurídico no século XIX. A objetividade do justo e do injusto depende sim da ação dos agentes, ao contrário do que entendia Villey. Mas o justo e o injusto são apenas parcialmente dependentes da ação voluntária (ENV, 8-9), pois sua justiça está tanto no modo como o sujeito passivo recebeu a ação quanto nas condições objetivas de avaliação do estado de coisas resultante da ação (ENV, 1-7).

Meu objetivo aqui restringiu-se à exegese do texto do LivroV da Ética Nicomaquéia, especialmente seus capítulos 1 e 9, como forma de demonstrar a falsidade da visão de que o justo e o injusto podem ser definidos sem se preocupar com conceitos de uma teoria da ação, como o conceito de ação voluntária, por exemplo. E essa análise é suficiente para demonstrar que as interpretações objetivistas puras, como a deVilley, são insuficientes para dar conta da complexidade da teoria aristotélica da justiça. E, muito embora não tenha sido objeto desse estudo, essas teorias parecem também insuficientes para dar conta da complexidade do fenômeno jurídico.

Aristóteles se revela muito mais sutil que o objetivismo puro deVilley, Weinrib e Gordley. Mas também é muito mais sutil que o simples voluntarismo que vê na vontade a única fonte de obrigações jurídicas. Creio que, com isso, o objetivo modesto que tracei no início foi cumprido.

Para uma melhor reconstrução da teoria aristotélica da justiça, é necessário, é claro, analisar mais detalhadamente a ligação entre a definição inicial e esta definição final do justo e do injusto. Do mesmo modo, é necessário fazer um estudo mais aprofundado desse tema em sua relação com outros livros da Ética Nicomaquéia. Mas isso é um trabalho diferente daquele a que me propus levar a cabo aqui.

${ }^{1}$ ParaVilley, é central sua tradução de to dikaion por "a coisa justa" ou por "o direito", de modo a poder remeter a Aristóteles a defesa de sua tese de que o direito é a coisa justa e é separado da 
moralidade, que seria prescritiva. No caso da primeira dessas traduções, "coisa justa", podemos simplesmente abandonar por erro categorial (to dikaion não é uma coisa). No caso da segunda, ela somente poderia ser utilizada se a tese estivesse correta, o que, como veremos, não está. Assim, mantenho a terminologia tradicional, traduzindo to dikaion simplesmente por "o justo", uma substantivação de um adjetivo neutro.

${ }^{2}$ Villey acredita que é a diferença entre justiça geral e justiça particular que nos dá a diferença entre direito e moralidade. Enquanto o direito seria "a coisa justa" segundo os critérios da justiça particular (ENV,2), a moralidade seria o justo legal ou geral (ENV, 1). Mas, ao focar nas diferenças entre esses, Villey esquece que há homonímia entre dikaion usado como justo segunda a lei e dikaion usado como justo segundo um critério de igualdade. Assim, o que Aristóteles fala em ENV, 1 e mais tarde em ENV, 9 se aplica a ambos os casos, e não apenas a um deles. Trata-se de conceitos homônimos em que um é englobado pelo outro. Ao não perceber isso,Villey se sente tentado a fazer inserir ali uma diferença artificial entre moralidade e direito, esquecendo-se que o justo em seu sentido particular é considerado por Aristóteles como parte do justo em seu sentido geral. Sendo assim, o que Aristóteles afirma sobre o justo geral deve também se aplicar ao justo particular.

${ }^{3}$ Horômen dê pantas tên toiautên exin boulomenous legein dikaiosunên af' hês praktikoi tôn dikaiôn eisi, kai af'hês dikaiopragousi kai boulonta ta dikaia: ton auton de tropon kai peri adikias, af'hês adikousi kai boulontai ta adika. dio kai hêmin prôton hôs en tupôi Hupokeistô tauta. (ENV,1 1129 a 7-11). Exceto quando de outro modo indicado, as traduções foram feitas a partir do texto da Loeb Classical Library (ARISTÓTELES, 1934) com consultas à tradução de H. Rackham que o acompanha, bem como às traduções de Terence Irwin (ARISTÓTELES, 1999) e W. D. Ross (ARISTÓTELES, 1984).

4 eilêfthô dê ho adikos posachôs légetai. dokei dê ho te paranomos adikos einai kai ho pleonektês kai anisos, hôste dêlon hoti kai [ho] dikaios estai ho te nomimos kai ho isos. (ENV,1 1129 a 31-34).

5 to men dikaion ara to nomimon kai to ison, to d'adikon to paranomon kai to anison. (ENV, 11129 a 34-35).

${ }^{6}$ Aqui Aristóteles se refere não apenas à lei ou convenção tal como é (nomos), mas também àquilo que deveria ser lei, enquanto produto da atividade legislativa (ta nomima) corretamente exercida (ver KRAUT, 2002, p. 114, n. 25).

7 Deve-se enfatizar que a nomenclatura "justiça geral" e "justiça particular" não tem correspondência no texto aristotélico, sendo devida aos comentadores. Apesar disso, expressa bem a distinção feita por Aristóteles entre duas virtudes às quais se dá o nome de justiça (hê dikaiosunê).

${ }^{8}$ Exceto, é claro, indiretamente, quando participam da elaboração da lei.

${ }^{9}$ poteron gar hôs alêthôs estin ekonta adikaisthai, ê ou all'akousion hapan, hôsper kai to adikein pan hekousion: kai ara pan outôs ê ekeinôs [hôsper kai to adikein pan ekousion], ê to men hekousion to d'akousion: homoiôs de kai epi tou dikaiousthai (to gar dikaiopragein pan hekousion). (EN V, 91136 a 15-22).

doispontos, Curitiba, São Carlos, vol. 10, n. 1, p.127-142, abril, 2013 
10 enion gar dikaiountai ouch hekontes. (ENV, 91136 a 22-23). Utilizo aqui a tradução brasileira de Mário da Gama Kury (ARISTÓTELES, 2001).

11 epeita kai tode diaporêseien an tis, poteron ho to adikon peponthôis, adikeitai pas ê estin: kata sumbebêkos gar endechetai ep'amfoterôn metalambanein tôn dikaiôn. (ENV, 91136 a 23-27).

${ }^{12}$ Ver capítulo anterior e ENV, 8. Utilizo a terminologia “objetivamente justo" para me referir ao que é justo ou injusto de acordo com a definição de EN V, 1, i.e., de acordo com aquilo que adiante chamarei de condições objetivas do justo. O mesmo se dá com a terminologia "objetivamente injusto".

${ }^{13}$ homoiôs de dêlon hoti kai epi tôn adikôn: ou gar tauton to tadika prattein tôi adikein oude to adika paschein tôi adikeisthai, homoiôs de kai epi tou dikaiopragein kai dikaiousthai; adunaton gar adikeisthai mê adikountos ê dikaiousthai mê dikaiopragountos. (ENV, 91136 a 26-29).

${ }^{14}$ Quem age voluntariamente conforme o que é injusto não necessariamente age injustamente, pois pode tê-lo feito com a concordância de quem sofre o que é injusto.

15 ê ouk orthos ho diorismos, alla prostheteon tôi blaptein eidota kai hon kai hôi kai hôs to para tên ekeinou boulêsin: blapteitai men oun tis hekôn kai tadika paschei, adikeitai d'outheis hekôn: outheis gar bouletai, oud'ho akratês, alla para tên boulêsin prattei: oute gar bouletai outheis ho mê oietai einai spoudaion, ho te akratês hou ouk oietai dein prattein prattei. (ENV, 91136 b 3-9).

\section{Referências bibliográficas:}

ARISTÓTELES. 1984. Nicomachean Ethics. Tradução de W. D. Ross revisada por J. O. Urmson. In: BARNES, J. (Organizador). The Complete Works of Aristotle: The revised Oxford translation. Tomo II. Princeton:

Princeton University Press.

ARISTÓTELES. 1999. Nicomachean Ethics. Tradução de Terence Irwin. 2. ed. Indianápolis: Hackett.

ARISTÓTELES. 2001. Ética a Nicômacos. Tradução de Mário da Gama Kury. 4. ed. Brasília: Editora UnB.

ARISTÓTELES. 1934. Nicomachean Ethics. Edição bilíngue com tradução de H. Rackham. (Loeb Classical Library). Cambridge, Massachusetts.

BEVILAQUA, Clovis. 1903. Do enrequecimento illegitimo. Logar que se lhe deve assignalar nos Codigos Civis. Revista Academica da Faculdade de Direito do Recife, Recife, ano XI, pp. 3-13. 
BOSTOCK, David. 2000. Aristotle's Ethics. Oxford: Oxford University Press.

GORDLEY, James. 2006. Foundations of Private Law. Oxford: Oxford University Press.

IRWIN, Terence. 1988. Aristotle's First Principles. Oxford: Clarendon. KRAUT, Richard. 2002. Aristotle. Oxford: Oxford University Press. MILLER JR., Fred D. 1995. Nature, Justice, and Rights in Aristotle's Politics. Oxford: Clarendon Press.

VILLEY, Michel. 1977. Esquisse historique sur le mot responsable. Archives de philosophie du droit, n. 22, p. 45-58.

VILLEY, Michel. 2003. Filosofia do direito. Tradução de Márcia Valéria Martinez de Aguiar. São Paulo: Martins Fontes.

WEINRIB, Ernest J. 1995. The Idea of Private Law. Cambridge, Massachusetts: Harvard University Press. 